\title{
Typical Gastroesophageal Reflux Disease in the General Adult Population in Cotonou: Prevalence and Associated Socio-Demographic Factors
}

\author{
Aboudou Raïmi Kpossou' ${ }^{*}$, Rodolph Koffi Vignon', Sewedo Aurel Chavelin Gnahoui', \\ Comlan N'déhougbèa Martin Sokpon'1, Carin Ahouada ${ }^{2}$, Colette Azandjèmè̀ ${ }^{3}$, Jean Séhonou ${ }^{1}$ \\ ${ }^{1}$ Hepato-Gastroenterology Department, National and University Hospital Hubert Koutoukou Maga (CNHU-HKM), Cotonou, \\ Benin Republic \\ ${ }^{2}$ Medicine Department, Allada Zone Hospital, Allada, Benin Republic \\ ${ }^{3}$ Regional Institute of Public Health (IRSP), Ouidah, Benin Republic \\ Email: *kpossou.raimi@yahoo.fr
}

How to cite this paper: Kpossou, A.R., Vignon, R.K., Gnahoui, S.A.C., Sokpon, C.N.M., Ahouada, C., Azandjèmè, C. and Séhonou, J. (2021) Typical Gastroesophageal Reflux Disease in the General Adult Population in Cotonou: Prevalence and Associated Socio-Demographic Factors. Open Journal of Gastroenterology, 11, 29-38.

https://doi.org/10.4236/ojgas.2021.112003

Received: November 22, 2020

Accepted: February 7, 2021

Published: February 10, 2021

Copyright $\odot 2021$ by author(s) and Scientific Research Publishing Inc. This work is licensed under the Creative Commons Attribution International License (CC BY 4.0).

http://creativecommons.org/licenses/by/4.0/ (c) (i) Open Access

\begin{abstract}
Introduction: Gastroesophageal Reflux Disease (GERD) is a common benign condition with a worldwide prevalence of between $5 \%$ and $45 \%$ in the adult population. Its prevalence in the general population is little known in Africa. The aim of this work was to study the prevalence of typical GERD in the general adult population of a large city and the associated socio-demographic factors. Patients and Methods: This was a prospectively collected, descriptive and analytical cross-sectional study that was conducted over a one-month period (June 2018). We included any person residing in the city of Cotonou for at least 6 months, aged 15 years or older, who had given consent for the study. The two-stage cluster sampling technique was used. The dependent variable was the typical gastroesophageal reflux defined by the heatburn-regurgitation association. Results: We had included 728 subjects. Of these, 255 had a typical GERD, i.e. a prevalence of $35 \%$. The mean age of the respondents was $31.9 \pm 13.2$ years with extremes of 15 and 88 years. There were 379 men (52.1\%) with a sex ratio of 1.08 . The study population was represented respectively by artisans $(29.3 \%)$, students $(26.6 \%)$ and traders/dealers $(20.3 \%)$. In terms of marital status, there were as many married and single subjects (48.2\%). In addition, $47 \%$ of the study population had a body mass index of less than $25 \mathrm{~kg} / \mathrm{m}^{2}$. In univariate analysis, the sociodemographic factors associated with typical GERD were: age (60 years and older): OR: 0.220 [95\% CI 07 - 0.63], $\mathrm{p}=0.005$ and marital status divorced/separated/widowed: OR:
\end{abstract}


0.32 [0.11 - 0.97], $\mathrm{p}=0.04$. Older age and divorced/separated/widowed status appear to be protective of the occurrence of GERD. Conclusion: Typical GERD was common in the adult population of Cotonou. It readily affected young (under 60 years of age), single or married subjects.

\section{Keywords}

Typical GERD, Prevalence, Socio-Demographic Factors, Cotonou

\section{Introduction}

Gastroesophageal Reflux Disease (GERD) is defined as the ascent of gastric or gastroduodenal contents above the gastroesophageal junction, without effort to vomit. This physiological phenomenon is considered pathological when it causes symptoms and/or structural damage (oesophagitis), affecting the well-being and quality of life of those who present it. Reflux of gastric contents is then in the majority of cases abnormally frequent and/or prolonged [1].

Symptoms of heatburn and regurgitation are considered typical defining GERD. In this case no further examination is necessary. The response to treatment will confirm the diagnosis [2]. However, many patients present with atypical manifestations of GERD, or those attributed to GERD. The most common "extra-esophageal" manifestations thought to be related to GERD are atypical chest pain, ear, nose and throat manifestations and chronic cough [2].

It is a common disease, affecting $20 \%-40 \%$ of the adult population in Western countries, of which $5 \%-10 \%$ have daily symptoms. The natural history of this disease is currently better known. It is marked by frequent non-use of the health care system and, at the same time, frequent self-medication; a tendency for symptoms to recur; and the rarity (but not absence) of severe complications [3]. GERD is a public health problem in the West [4]. Its prevalence is high in the West, as is its socio-economic cost. It affects the quality of life of patients and puts them at long-term risk of oesophageal adenocarcinoma via the endobrachyesophagus.

Indeed, typical GERD is a very common condition in developed countries [1]. Its prevalence is increasing due to the growth of obesity [5] [6]. In France, the prevalence of typical GERD is $5 \%-10 \%$ with daily onset of symptoms, $15 \%$ $20 \%$ with at least weekly onset of symptoms, $30 \%-45 \%$ with at least monthly onset of symptoms. However, these data underestimate the true prevalence of GERD due to the existence of atypical forms which often escape investigation [1]. In a study in Finland, a prevalence of $22 \%$ was reported in patients admitted for endoscopy [7].

In Africa few studies have been published on GERD. They mainly concern hospital series, endoscopic studies and a few studies in the general population. A prevalence of $24 \%$ in general medical consultations has been reported in Tunisia [8]. A study in Dakar found a frequency of $16.75 \%$ in patients referred for diges- 
tive endoscopy [9]. A study in the Abidjan population in 2013 showed that the prevalence of typical GERD was $14.5 \%$ [10]. The overall prevalence of GERD was $34.7 \%$ in the consulting population in Bujumbura, Burundi, with a predominance of females ( $40.3 \%$ versus $28 \%$ in males) and Helicobacter pylori infection did not appear to influence the presence of GERD [11]. Several socio-demographic and lifestyle factors have been implicated in the occurrence of GERD according to a study of students at the University of Burundi. These were: age, alcohol, obesity and tobacco [12].

Other work has been carried out in South America, particularly in Brazil, where the prevalence was $7.3 \%$, increasing with age, especially after the age of 55 and higher among women, and where diet, gender and anxiety are predominant influencing factors [13]. In Uruguay's urban population it is 11.6\% [14]. In Argentina, typical symptoms of GERD are widespread and frequently associated with dysphagia and non-cardiac chest pain [15]. In Saudi Arabia, GERD affects more divorced/widowed, obese and sedentary people [16].

The interest in GERD stems from its chronic nature, its significant impact on patients' quality of life and its possible progression to adenocarcinoma of the oesophagus [17]. It should be noted that its diagnostic and therapeutic management constitutes a financial burden for society in terms of drug consumption and the search for therapeutic alternatives for long-term management [18].

A study carried out in Cotonou in digestive endoscopy centres in 2014 found a prevalence of $25.65 \%$ for GERD [19]. In the absence of previous data on this condition in the general population in the Republic of Benin, we considered it appropriate to carry out this work.

The aim of this work was to study the prevalence of typical GERD in the general adult population of a large city and the socio-demographic factors associated with it.

\section{Methods}

This was a descriptive and analytical cross-sectional study, with prospective data collection over a one-month period (in June 2018). We included all persons who had been resident in the city of Cotonou for at least 6 months, aged 15 years or older, and who had given their consent for the study. We didn't include subjects who were hospitalized during the inclusion period, and those who were unable to speak or mentally handicapped. The probabilistic method was used. The sample size calculated by the Schwartz formula was 728 subjects. The two-stage cluster sampling technique (neighbourhoods then individuals) was used, considering all neighbourhoods in the city as clusters. Thus, a total of 143 clusters were counted.

The dependent variable was the typical gastroesophageal reflux defined by the association of heatburn (ascending retro-sternal, burn-type pain, perceived in the postprandial period and often during trunk anteflexion or in right dorsal or lateral decubitus position) and regurgitation (reflux fluids arriving in the mouth 
without vomiting). The independent variables were socio-demographic (gender, age, ethnicity, occupations, marital status), history (associated conditions: diabetes, hypertension, gastric or duodenal ulcer; in women: number of pregnancies and childbirth, current pregnancy), lifestyle (use of tobacco, alcohol, tea, coffee, chocolate, medicines, foods (fatty or spicy, sour, acidic or fermented), drugs), and clinical data (epigastralgia, dysphagia; asthmatiform dyspnea; digestive bleeding; date of onset of symptoms).

Statistical analyses were done in SAS version 9.4. Proportions were calculated on the categorical variables. Univariate logistic regression analysis was used to identify the socio-demographic factors associated with typical GERD. All univariate variables were introduced into the multivariate model. High p-value variables were progressively taken out of the model until a final model with p-value variables below 0.05 was completed. Confidence intervals were calculated with a $5 \%$ margin of error, and p-value is considered statistically significant if $\mathrm{p}<0.05$.

From an ethical point of view, the study was not submitted to a local ethics committee. Nevertheless, verbal informed consent was obtained from the participants. Furthermore, confidentiality and respect for the human person were observed during data collection and processing.

\section{Results}

\subsection{Characteristics of the Study Population}

Of the 728 subjects included, there were 349 women (47.9\%) and 379 men (52.1\%), i.e. a sex-ratio of 1.08 . The majority of the subjects in our study $(52.5 \%)$ were young people between 15 and 29 years of age. Furthermore, the average age was $31.9 \pm 13.2$ years, with extremes of 15 and 88 years. Within the study population, there was a clear predominance of Fon and related ethnic groups (47.2\%). The study population was represented respectively by craftsmen $(29.3 \%)$, students (26.6\%) and dealers (20.3\%). In terms of marital status, there were as many married and single subjects (48.2\%). Concerning the body mass index (BMI), $47 \%$ of the study population had a BMI of less than $25 \mathrm{~kg} / \mathrm{m}^{2}$, and $53 \%$ were overweight or obese.

\subsection{Prevalence of Typical GERD}

Of the 728 subjects included during the study period, 255 had typical GERD according to the defined criteria, i.e. a prevalence of 35\%. Among these 255 patients, there were 126 men and 129 women, i.e. a sex-ratio of 0.98 . The prevalence of typical GERD was $33.2 \%$ in men (126/379) compared to $37 \%$ in women (129/349).

\subsection{Related Socio-Demographic Factors}

In univariate analysis, the socio-demographic factors found to be associated with the occurrence of typical GERD were: age (60 years and older) with OR of 
0.220 [95\% CI: $07-0.63$ ], $\mathrm{p}=0.005$ and marital status divorce/separated/widowed with OR of 0.32 [95\% CI: $0.11-0.97$ ], $\mathrm{p}=0.04$. Old age and divorce/separation/widowhood status appear to be protective of the occurrence of GERD. Fewer cases were diagnosed in patients with these characteristics (Table 1). Despite a slight female predominance among GERD patients, gender does not appear to be associated with typical GERD in our study ( $\mathrm{p}$ ranging from 0.09

Table 1. Univariate analysis study of the socio-demographic factors associated with typical GERD.

\begin{tabular}{|c|c|c|c|c|c|}
\hline & \multicolumn{2}{|c|}{ Typical GERD } & \multicolumn{3}{|c|}{ Univariate analysis } \\
\hline & Yes & No & OR & CI $95 \%$ & p-value \\
\hline \multicolumn{6}{|l|}{ Gender } \\
\hline Male & $126(33.25)$ & $253(66.75)$ & 1 & & \\
\hline Female & $129(36.96)$ & $220(63.04)$ & 1.17 & $0.86-1.59$ & 0.29 \\
\hline \multicolumn{6}{|l|}{ Age (years) } \\
\hline $15-29$ & $144(37.70)$ & $238(62.30)$ & 1 & & \\
\hline $30-44$ & $77(34.68)$ & $145(65.32)$ & 0.87 & $0.62-1.24$ & 0.45 \\
\hline $45-59$ & $30(33.33)$ & $60(66.67)$ & 0.82 & $0.50-1.34$ & 0.44 \\
\hline 60 and over & $4(11.76))$ & $30(88.24)$ & 0.22 & $0.07-0.63$ & 0.005 \\
\hline \multicolumn{6}{|l|}{ Ethnicity $(n=723)^{*}$} \\
\hline Adja & $14(33.33)$ & $28(66.67)$ & 1 & & \\
\hline Nago/Mahi/Fon & $124(36.36)$ & $217(63.64)$ & 1.14 & $0.58-2.25$ & 0.69 \\
\hline Goun & $26(25.24)$ & $77(74.76)$ & 0.67 & $0.31-1.47$ & 0.32 \\
\hline Pedah/Mina & $22(45.83)$ & $26(54.17)$ & 1.69 & $0.71-3.98$ & 0.22 \\
\hline Yoruba & $15(35.71)$ & $27(64.29)$ & 1.11 & $0.45-2.73$ & 0.81 \\
\hline Bariba/Dendi/Ahoussa/Cotocoli/Djerma & $9(32.14)$ & $19(67.86)$ & 0.94 & $0.34-2.62$ & 0.91 \\
\hline Foreigners & $12(37.50)$ & $20(62.50)$ & 1.20 & $0.45-3.13$ & 0.71 \\
\hline Aizo/Cotafon/Xwla & $15(28.85)$ & $37(71.15)$ & 0.81 & $0.33-1.95$ & 0.63 \\
\hline Others & $15(42.86)$ & $20(57.14)$ & 1.50 & $0.59-3.79$ & 0.39 \\
\hline \multicolumn{6}{|l|}{ Occupations } \\
\hline Craftsman, & $85(39.91)$ & $128(60.09)$ & 1 & & \\
\hline Traders/dealers & $53(35.81)$ & $95(64.19)$ & 0.84 & $0.54-1.29$ & 0.43 \\
\hline Grower/household/farmer & $14(30.43)$ & $32(69.57)$ & 0.65 & $0.33-1.30$ & 0.23 \\
\hline Students/pupils & $66(34.02)$ & $128(65.98)$ & 0.77 & $0.51-1.16$ & 0.22 \\
\hline Civil servants/employees & $35(30.70)$ & $79(69.30)$ & 0.66 & $0.41-1.08$ & 0.1 \\
\hline Others & $2(15.38)$ & $11(84.62)$ & 0.27 & $0.05-1.26$ & 0.09 \\
\hline \multicolumn{6}{|l|}{ Marital status } \\
\hline Single & $125(35.61)$ & $226(64.39)$ & 1 & & \\
\hline Divorced/separated/widowed & $4(15.38)$ & $22(84.62)$ & 0.32 & $0.11-0.97$ & 0.04 \\
\hline Married & $126(35.90)$ & $225(64.10)$ & 1.01 & $0.74-1.37$ & 0.93 \\
\hline
\end{tabular}


to 0.43 depending on occupational category). Similarly, occupation and ethnicity were not associated with typical GERD ( $\mathrm{p}$ ranging from 0.22 to 0.91 depending on the ethnic category).

In multivariate analysis, only age over 60 years was consistently associated with the occurrence of typical GERD with a risk similar to that observed in univariate analysis. Taking into account the other socio-demographic characteristics, it therefore appears that older subjects are at lower risk of developing GERD compared to younger subjects with an $\mathrm{AOR}=0.21$ [95\% CI: $0.07-0.63], \mathrm{p}=$ 0.005 (Table 2). Gender, ethnicity, occupation, and marital status do not appear to be statistically associated with GERD in multivariate analysis.

Table 2. Multivariate analysis of socio-demographic factors associated with typical GERD.

\begin{tabular}{|c|c|c|c|c|c|}
\hline & \multicolumn{2}{|c|}{ Typical GERD } & \multicolumn{3}{|c|}{ Multivariate analysis } \\
\hline & Yes & No & AOR & CI $95 \%$ & p-value \\
\hline \multicolumn{6}{|l|}{ Gender } \\
\hline Male & $126(33.25)$ & $253(66.75)$ & & & \\
\hline Female & $129(36.96)$ & $220(63.04)$ & & & \\
\hline \multicolumn{6}{|l|}{ Age } \\
\hline $15-29$ & $144(37.70)$ & $238(62.30)$ & 1 & & \\
\hline $30-44$ & $77(34.68)$ & $145(65.32)$ & 0.78 & $0.52-1.16$ & 0.22 \\
\hline $45-59$ & $30(33.33)$ & $60(66.67)$ & 0.72 & $0.42-1.23$ & 0.23 \\
\hline 60 and over & $4(11.76))$ & $30(88.24)$ & 0.21 & $0.07-0.63$ & 0.005 \\
\hline \multicolumn{6}{|l|}{ Ethnicity $(\mathrm{n}=723)^{*}$} \\
\hline Adja & $14(33.33)$ & $28(66.67)$ & & & \\
\hline Nago/Mahi/Fon & $124(36.36)$ & $217(63.64)$ & & & \\
\hline Goun & $26(25.24)$ & $77(74.76)$ & & & \\
\hline Pedah/Mina & $22(45.83)$ & $26(54.17)$ & & & \\
\hline Yoruba & $15(35.71)$ & $27(64.29)$ & & & \\
\hline Bariba/Dendi/Ahoussa/Cotocoli/Djerma & $9(32.14)$ & $19(67.86)$ & & & \\
\hline Foreigners & $12(37.50)$ & $20(62.50)$ & & & \\
\hline Aizo/Cotofon/Xwla & $15(28.85)$ & $37(71.15)$ & & & \\
\hline Others & $15(42.86)$ & $20(57.14)$ & & & \\
\hline \multicolumn{6}{|l|}{ Occupations } \\
\hline Craftsman, & $85(39.91)$ & $128(60.09)$ & 1 & & \\
\hline Traders/dealers & $53(35.81)$ & $95(64.19)$ & 0.87 & $0.56-1.36$ & 0.55 \\
\hline Grower/household/farmer & $14(30.43)$ & $32(69.57)$ & 0.78 & $0.39-1.59$ & 0.50 \\
\hline Students/pupils & $66(34.02)$ & $128(65.98)$ & 0.65 & $0.41-1.02$ & 0.06 \\
\hline Civil servants/employees & $35(30.70)$ & $79(69.30)$ & 0.73 & $0.44-1.19$ & 0.21 \\
\hline Others & $2(15.38)$ & $11(84.62)$ & 0.30 & $0.06-1.44$ & 0.13 \\
\hline \multicolumn{6}{|l|}{ Marital status } \\
\hline Single & $125(35.61)$ & $226(64.39)$ & & & \\
\hline Divorced/separated/widowed & $4(15.38)$ & $22(84.62)$ & & & \\
\hline Married & $126(35.90)$ & $225(64.10)$ & & & \\
\hline
\end{tabular}




\section{Discussion}

Our study found that the prevalence of typical GERD was 35\% in the general adult population in Cotonou. This result is almost identical to that reported by Ntagirabiri et al. [11] in 2013 in a study carried out on a population of consultants in Bujumbura (34.7\%). This prevalence is high, compared to those obtained by some authors: $14.5 \%$ found by Lohoues-Kouacou et al. [17] in a general population studyin Abidjan; 24.8\% reported by Ben Chaabane et al. [8] during a study in patients received for general medicine consultation in Monastir; 24.86\% found by Sogbossi [19] in 2014 in digestive endoscopy units in Cotonou.

Population-based studies suggest that GERD is a common condition with a prevalence of $10 \%-20 \%$ in Western Europe and North America [4] [20]. The prevalences found in South America (10\%) and Turkey (11.9\%) are similar to those in European countries [13] [21]. This difference could be explained by the methodology of the studies as well as the types of population considered. It should also be noted that our study only considered typical GERD, defined by the combination of heatburn and regurgitation.

The mean age of our participants was $31.89 \pm 13.24$ years with extremes at 15 and 88 years. Patients aged 15 to 29 years accounted for $52.5 \%$ of the total population (a relatively young population as in most studies in Africa). A similar average age was found by Batakou et al. in Benin [22] and Mansour-Ghanaei in Iran [23]. The average age was 43 years in the consultant population in Burundi [11].

In univariate analysis in our study there was a statistically significant relationship between age and typical GERD. Subjects under 60 years of age were the most affected $(p=0.005)$. This association (typical GERD-age) was not found in Iran [23], Côte d'Ivoire [17], Tunisia [8] or Saudi Arabia [16]. The most affected subjects were over 55 years old according to Prado et al. in Brazil [13]. Yonem et al. [24] found a significant association between the age range 60-69 years and typical GERD in Turkey. In a study of GERD symptoms in the Greek population [25], Spantideas found that subjects aged 65 - 79 years were most at risk [25]. This difference between our results and those of the above mentioned studies could be explained by the influence of other factors such as diet, obesity which can vary from one population to another and according to age.

In our study, the sex-ratio was 0.98 for GERD patient. These results are similar to the female predominance found in most studies: Mansour-Ghanaei et al. [23]: 0.44; Lohoues-Kouacou et al. [17]: 0.86; Sogbossi et al. [19]: 0.52; Batakou et al. [22]: 0.61 . However, there was no statistically significant relationship between gender and the occurrence of typical GERD in our study. This result is similar to that of the Saudi study [16] and the results of the Greek population study [25]. This is in contrast to other studies (mostly hospital-based) where female was an associated factor [17] [23].

A clear predominance of Fons and relatives was noted in a proportion of $47.16 \%$ of our sample. This reflects the geographical affiliation of these patients. 
Indeed, the study was carried out in the city of Cotonou in the southern region of Benin where the Fon ethnic group is in the majority. Craftsmen, students and shopkeepers represented the majority of the population studied. This confirms Cotonou's status as the economic capital of the city, which also has a good concentration of education centres. No link was found between these two characteristics (ethnicity and occupation) and typical GERD. This result is identical to that found in Sivas, Turkey [24].

We counted as many single people as married (48.21\%), 3.57\% widows/widowers/separated/divorced. There was a statistically significant relationship between marital status (married, single) and typical GERD $(\mathrm{p}=0.04)$. This result is similar to that found by Alsuwat et al. [16] in the population of Saudi Arabia where marital status was associated with typical GERD, which affected widowed and divorced people much more. The reasons for this association deserve to be elucidated by further studies taking into account dietary habits, psychological stress level...

Weaknesses of this work include the fact that some participants did not know their exact age; financial difficulties did not allow the research to be extended to a larger and more representative sample of the Cotonou population. However, this study was, to our knowledge, the first to be carried out in Benin on GERD in the general population. It allowed us to assess the prevalence of typical GERD in the general population but also to assess the socio-demographic factors associated with its occurrence.

\section{Conclusion}

The prevalence of typical GERD was 35\% in the adult population in Cotonou. As sociodemographic factors, youthful age and marital status (single or married) were associated with its occurrence in our series. Further studies are needed, including endoscopic examinations to support these data.

\section{Conflicts of Interest}

The authors do not declare any conflict of interest.

\section{Contributions of Authors}

All the authors were involved in the active writing and editing of the article. All authors have read and approved the final version of the manuscript.

\section{References}

[1] Collégiale des universitaires en hépato-gastro-entérologie. (2015) Hépato-gastroentérologie Chirurgie digestive. Elsevier Masson SAS, Issy-les Moulineaux cedex, Chapitre 8, Item 268 - UE 8-Reflux gastro-œsophagien chez le nourrisson. chez l'enfant et chez l'adulte, Hernie hiatale, 87-95.

[2] Zerbib, F. and Roman, S. (2014) Prise en charge thérapeutique des formes typiques et atypiques de RGO. Hépato-Gastro \& Oncologie Digestive, 21, 36-46.

[3] El Agheb, M.O.M. (2015) Impact du reflux gastro-œsophagien sur la qualité de vie 
des patients: A propos d'une série de 100 patients [Mémoire d'obtention du diplôme de spécialité en Hépato-gastroentérologie]. Université Sidi Mohammed Ben Abdellah, Maroc, $44 \mathrm{p}$.

[4] Dent, J., El-Serag, H.B., Wallander, M.A. and Johansson, S. (2005) Epidemiology of Gastro-Oesophageal Reflux Disease: A Systematic Review. Gut, 54,710-717. http://dx.doi.org/10.1136/gut.2004.051821

[5] El-Serag, H. (2008) Role of Obesity in GORD-Related Disorders. Gut, 57, 281-284. http://dx.doi.org/10.1136/gut.2007.127878

[6] Festi, D., Scaioli, E., Baldi, F., Vestito, A., Pasqui, F., Di Biase, A.R., et al. (2009) Body Weight, Lifestyle, Dietary Habits and Gastroesophageal Reflux Disease. World Journal of Gastroenterology, 15, 1690-1701. http://dx.doi.org/10.3748/wjg.15.1690

[7] Voutilainen, M., Sipponen, P., Mecklin, J.P., Juhola, M. and Färkkilä, M. (2000) Gastroesophageal Reflux Disease: Prevalence, Clinical, Endoscopic and Histopathological Findings in 1,128 Consecutive Patients Referred for Endoscopy Due to Dyspeptic and Reflux Symptoms. Digestion, 61, 6-13.

https://doi.org/10.1159/000007730

[8] Ben chaabane, N., El Jeridi, N., Ben Salem, K., Loghmari, H., Melki, W., Bdioui, F., et al. (2012) Prevalence of Gastroesophageal Reflux in Tunisian Primary Care Population Determined by Patient Interview. Disease of the Esophagus, 25, 4-9. https://doi.org/10.1111/j.1442-2050.2011.01205.x

[9] Diouf, M.L., Dia, D., Mbengue, M., et al. (2002) Le Reflux Gastro-œsophagien de l'adulte: Aspects cliniques et endoscopiques au CHU Le Dantec de Dakar. Dakar Medical, 47, 142-146.

[10] Sonnenberg, A. and El Serag, H.B. (1999) Clinical Epidemiology and Natural History of Gastroesophageal Reflux Disease. Yale Journal of Biology and Medicine, 72 , $81-92$.

[11] Ntagirabiri, R., Mumana, A., Baransaka, E., Niyonzima, S. and Ndayishimiye, H. (2013) Reflux gastro-œsophagien dans la population consultant à Bujumbura. Journal Africain d Hépato-Gastroentérologie, 7, 204-207. https://doi.org/10.1007/s12157-013-0496-6

[12] Ntagirabiri, R., Niyonzima, S., Mumana, A.L., and Ndabaneze, E. (2013) Reflux gastro-œsophagien chez l'adulte jeune africain: Cas des étudiants de l'Université du Burundi. Journal Africain d' Hépato-Gastroentérologie, 7, 192-195. https://doi.org/10.1007/s12157-013-0489-5.

[13] Prado, J., Moraes-Filho, P., Chinzon, D., et al. (2004) Gastro-Esophageal Reflux Disease: Prevalence and Management in Brazil. Best Practice \& Research Clinical Gastroenterology, 18, 23-26. https://doi.org/10.1016/j.bpg.2004.06.008

[14] Dacolla, C., Umpierrea, V., Tomassob, G., Saona, G., Alemán, A., Luisa Cafferata, M., et al. (2012) Prevalencia de la enfermedad por reflujo gastroesofágico en Uruguay. Gastroenterología y Hepatología, 35, 460-467. https://doi.org/10.1016/j.gastrohep.2012.02.008

[15] Chiocca, J.C., Olmos, J.A., Salis, G.B., Soifer, L.O., Higa, R. and Marcolongo, M. (2005) Prevalence, Clinical Spectrum and Atypical Symptoms of Gastro-Oesophageal Reflux in Argentina: A Nationwide Population-Based Study. Alimentary Pharmacology \& Therapeutics, 22, 331-342. https://doi.org/10.1111/j.1365-2036.2005.02565.x

[16] Alsuwata, O.B., Alzahrania, A.A., Alzhrania, M.A., Alkhathami, A.M., Eid, M. and Mahfouz, M. (2018) Prevalence of Gastroesophageal Reflux Disease in Saudi Arabia. Journal of Clinical Medicine Research, 10, 221-225. 
https://doi.org/10.1159/000007730

[17] Lohouès-Kouacou, M.J., Assi, C., Ouattara, A., Coulibaly, J.-K., Ebela, C., Koné, A., et al. (2013) Prévalence du reflux gastro-œsophagien typique à Abidjan. Journal Africain d Hépato-Gastroentérologie, 7, 117-121. https://doi.org/10.1007/s12157-013-0465-4

[18] Galmiche, J.P., Cadiot, G., Matuchansky, C., and Mignon, M. (2005) Le reflux gastro-œsophagien de l'adulte. Ellipses Editions Marketing S.A, Paris, 749 p.

[19] Sogbossi, N.L.D. (2014) Reflux gastro-œsophagien à Cotonou: Aspects épidémiologiques, cliniques, endoscopiques et thérapeutiques. Thèse Médecine. Universitéd'Abomey-Calavi, Bénin, $134 \mathrm{p}$.

[20] Stanghellini, V. (1999) Relationship between Upper Gastrointestinal Symptoms and Lifestyle, Psychosocial Factors and Comorbidity in the General Population: Results from the Domestic/International Gastroenterology Surveillance Study (DIGEST). Scandinavian Journal of Gastroenterology, 231, 29-37.

[21] Bor, S., Mandiracioglu, A., Kitapcioglu, G., Caymaz-Bor, C., Gilbert, R.J. (2005) Gastroesophageal Reflux Disease in a Low-Income Region in Turkey. American Journal of Gastroenterology, 100, 759-765.

[22] Batakou JP. (2017) Manifestations ORL du RGO au CNHU-HKM et CSH Sainte Léonie de Cotonou [Mémoire d'obtention du diplôme spécialisé en ORL]. Universitéd'Abomey-Calavi, Bénin, 62 p.

[23] Mansour-Ghanaei, F., Joukar, F., Atshani, S.M., Chagharvand, S. and Souti, F. (2013) The Epidemiology of Gastroesophageal Reflux Disease: A Survey on the Prevalence and the Associated Factors in a Random Sample of the General Population in the Northern Part of Iran. International Journal of Molecular Epidemiology and Genetics, 4, 175-182.

[24] Yonem, O., Sivri, B., Ozdemir, L., Nadir, I., Yüksel, S. and Uygun, Y. (2013) Gastroesophageal Reflux Disease Prevalence in the City of Sivas. Turkish Journal of Gastroenterology, 24, 303-310. https://doi.org/10.4318/tjg.2013.0256

[25] Spantideas, N., Drosou, E., Bougea, A., and Assimakopoulos, D. (2016) Gastroesophageal Reflux Disease Symptoms in the Greek General Population: Prevalence and Risk Factors. Clinical and Experimental Gastroenterology, 9, 143-149. https://doi.org/10.2147/CEG.S103485 